劉 RESENHAS

326 


\section{A negritude viva em Terra negra, de Cristiane Sobral}

Dileane Fagundes de Oliveira ${ }^{1}$

É interessante refletir a respeito da criação literária de escritores que assu mem a identidade afro-brasileira e lançam-se no mundo da escrita, desestabilizando um sistema hegemônico que preconiza a invisibilidade discursiva do negro no Brasil. Dentre esses autores, ressaltamos a voz de Cristiane Sobral, pela natureza questionadora de sua escrita e pelo valor simbólico de suas reflexões a respeito da identidade negra. De forma atenta e comprometida com o cenário sociopolítico e cultural brasileiro, a escrita de Cristiane Sobral tem contribuído para revisitar, resgatar e legitimar a participação da mulher afrodescendente como sujeito da sua própria história, e assim contrapor a visão estereotipada de sua representação.

Nesse sentido, ao se aceitar o convite para adentrar em Terra negra (2017), percebe-se a necessidade de compreender as nuances internas e externas ao texto. Terra negra é um território fecundo, e a sua leitura leva a repensar a existência humana, a história brasileira e o aparato cultural que circunda os brasileiros. Nessa leitura, transitamos pelos caminhos do amor: somos seduzidos pelo erotismo, viajamos ao passado para revisitarmos nossos ancestrais, desejamos estar em Aruanda e testemunhar a história dos excluídos. Percorremos cada canto do mundo onde há uma voz negra. O arcabouço de mais de 70 poemas

\footnotetext{
${ }_{1}^{1}$ Doutoranda em Letras, com pesquisa intitulada $A$ construção do feminino nos romances Fundador, $A$ doce canção de Caetana e A república dos sonhos, de Nélida Piñon.
} 
que compõem esse livro-planeta revelam uma poética desafiadora e inquietante de resistência, testemunho consciente da experiência vivida, do reconhecimento e autoconhecimento. De forma muito consciente, Sobral apresenta-nos um perfeito equilíbrio entre o estético e o político.

Cristiane Sobral marca a terra com suas pegadas, demarca seu território, exalando cor, poesia, luta, sensibilidade e ousadia. A autora figura entre os escritores contemporâneos na antologia Literatura e afrodescendência no Brasil, de Eduardo de Assis Duarte. Desde 2014, ocupa a cadeira de número 34 na Academia de Letras do Brasil (no Distrito Federal). Além de poeta e escritora de contos, Cristiane Sobral, que nasceu na Zona Oeste do Rio de Janeiro, no bairro Coqueiros, em 1974, é autora teatral, arte-educadora e atriz. Foi, inclusive, a primeira atriz negra a formar-se em Interpretação Teatral pela Universidade de Brasília, em 1990.

Cristiane Sobral começou a se tornar conhecida pela sua escrita literária a partir da sua primeira publicação nos Cadernos Negros, em 2000. Seguiu publicando nesta e em outras antologias poéticas, até publicar o seu primeiro livro em 2010, intitulado Não vou mais lavar os pratos. No mesmo ano, publicou o livro de contos Espelhos, miradouros, dialéticas da percepção. Em 2011, lançou uma segunda edição de Não vou mais lavar os pratos. Em 2014, publicou mais um livro de poemas, intitulado Só por hoje vou deixar meu cabelo em paz (2014). Publicou também $O$ tapete voador (2016), livro de contos; Olhos de azeviche (2017), coletânea de contos e de crônicas; e Terra negra (2017), seu mais recente livro de poemas.

Iniciamos a leitura do livro guiados pela densidade poética de Elisa Lucinda, claramente uma escolha afetiva, pois a prefaciadora de Terra Negra e Cristiane Sobral são vozes destoantes em um território comum. No prefácio intitulado "A carta da terra", Lucinda apresenta Cristiane Sobral como a pérola de sua tribo e nos convida a uma conversa histórica, sincera, lírica e corajosa:

Cristiane Sobral nos desnuda com uma poesia cheia de personalidade, cores, aromas, densos enredos e escreve como tribo. Conhecedora. Caminha sem solidão porque traz as hordas dos 
povos em diáspora inebriados e entrelaçados em sua narrativa ética, estética e caudalosa. Curiosa sua arte, lindo o seu tear, minha querida Cristiane Sobral! Embora você já seja imortal, as academias ainda desfilam seus pobres ares de eurocêntricas nobrezas e pouco costume de não portar vozes não oficiais. A voz de uma mulher negra é a voz que se nega ao silenciamento, a voz que se impõe à porta da Casa Grande e entra. Arrebenta a tranca e ainda tem que provar, a cada balcão, o que é, quem é, e porque o é. Cansa até. Como a poesia é feita do impacto entre a poeta ou o poeta e sua experiência de viver, está presente todo o tempo, nas escuridões de Terra negra a luta existencial de todas nós (LUCINDA In: SOBRAL, 2017, p. 12).

A voz que Elisa Lucinda diz negar-se ao silêncio e que tece uma poesia forjada na experiência de viver está presente em todos os poemas. Tal temática é recorrente em sua obra, e nos instiga a pensarmos como é construída a identidade do negro nesses poemas. Partimos dos poemas "Eu sou" e "Quem sou”, os títulos de antemão já nos remetem a uma certa afirmação de uma subjetividade. É interessante ressaltar que essa construção identitária é articulada por um viés afirmativo, ou seja, coloca o negro como sujeito, protagonista de sua história, de sua cultura e da sua subjetividade promovendo a negação dos estigmas, estereótipos, submissão e objetificação. Percebemos uma correspondência com a colocação de Cuti (2010), ao afirmar que a discriminação, ou seja, a rejeição do outro por desqualificação, não se manifesta apenas no relacionamento entre as pessoas, mas também no ato da produção cultural, pois quando o escritor produz seu texto, evoca seu acervo de memórias.

No poema "Quem sou" (2017, p. 62), Sobral revela um eu-lírico que afirma sua negritude, contrapondo-se a um racismo velado implícito nas palavras morena, mulata e exótica. Essas palavras criam uma imagem a qual a mulher negra não se identifica. O eu-lírico feminino não quer ser visto como o exótico, ou seja, como o outro, o diferente, mas sim como todas as mulheres. Na última estrofe, ela reitera o orgulho de ser negra, de ser a voz de muitas mulheres que lutaram e lutam pelo direito de ser e de poder exibir sua negritude. A negritude pode ser entendida aqui pela concepção de Munanga: “uma operação de desintoxicação semântica e de 
constituição de um novo lugar de inteligibilidade da relação consigo, como com os outros e com o mundo" (MUNANGA, 2009, p. 53). Nesse poema, Sobral faz um trabalho de ressignificação semântica da palavra negra despojada da valoração negativa, contrariando, assim, o sentido hegemônico que se perpetuou na língua brasileira. A identidade é concebida na percepção de si como um sujeito consciente de seu poder e no poder de luta de seus antepassados.

Nessa ideia de negação dos estereótipos e da submissão no poema "Eu sou", o eu poético coloca-se no lugar daqueles que sofreram e ainda sofrem com o racismo. Evoca a representatividade de escritores e cantores negros, coloca em evidencia a cultura negra, a autonomia e a voz do negro como uma maneira de desafiar e de desconstruir o racismo. Assim como nos outros poemas, está presente aqui a mulher que se assume como negra, livre e linda. E responde ao racismo que teima em bater a sua porta: "O racismo não é ninguém / mas eu sou" (SOBRAL, 2017, p. 100).

Os versos desse poema promovem uma autoimagem positiva, que impulsiona o eu-lírico à luta e à conquista da desestabilização do racismo, com a certeza do valor da negritude. Como afirma Elisa Lucinda, é a voz brotada de uma pele preta, experiência de viver, presente todo o tempo, é a luta existencial de todas as mulheres negras. Assumir esse lugar de fala é também uma postura ética, como afirma Rosane Borges (apud. RIBEIRO, 2017, p. 84): "saber o lugar de onde falamos é fundamental para pensarmos as hierarquias, as questões de desigualdade, pobreza, racismo e sexismo". Apesar da violência sofrida no passado, das injustiças infligidas ainda hoje, a resistência se constrói no desejo coletivo, pois se o sofrimento atinge a todos, de alguma forma o futuro também deve ser compartilhado.

Os poemas de Sobral transgridem as representações estereotipadas, privilegiando a beleza, a cultura e a intelectualidade das mulheres negras. A escrita de Sobral apresenta-se investida, sobretudo, de compromisso social, tratando de assuntos concernentes à mulher negra e ao preconceito com o negro, refletindo 
uma preocupação com a construção de uma identidade negra autêntica e sem máscaras.

Já no poema "Nó na garganta", o eu-lírico constrói um contradiscurso a fim de questionar não só o padrão de beleza hegemônico, mas a maneira de olhar de um "outro", que censura, critica e deprecia o que lhe é diferente. É o outro quem determina o que é "diferente" e apresenta soluções para moldar esta diferença em relação ao padrão normativo. A relação que prevalece aqui é aquela que inferioriza e oprime o diferente. No entanto, a repetição dos versos "eu sei", revelam a consciência do eu lírico frente aos padrões culturais dominantes. A voz poética denuncia o mito da democracia racial por meio da metáfora da pomba branca encardida da paz, ou seja: por mais que se tente dissimular, o racismo ainda mostra suas nuances, às vezes de maneira mais agressiva, outras de maneira mais branda, porém persistentemente.

As palavras "tempo" e "trampo" (no poema "Nó na garganta") remetem ao preconceito relacionado à escravização do negro; por isso, o desmascaramento do outro que culpa a herança cultural que teima em acompanhar definição do negro na sociedade. Contra a ideologia do embranquecimento, a voz negra enuncia que, apesar do nó na garganta e de quase perder a fé na humanidade, ela só pode ser o que é, ou seja, a mulher negra insubmissa aos padrões e modelos estéticos racistas.

A negritude é evidente também nos poemas metalinguísticos "Página preta”, “Poesia preta feminina”, "Legado" e "Criar é verbo de ação". Nesses poemas, percebemos o quanto é marcante o empenho em construir representações que revertam aquelas que aparecem marcadas por inferioridade e exclusão nas práticas culturais hegemônicas e reafirmadas na literatura brasileira. Para construir uma reflexão sobre o questionamento e a consequente ressignificação das imagens das mulheres negras representadas na literatura brasileira, é importante atentar para a escrita de Sobral. Ela traz marcas de subjetivação do sujeito mulher-negra, bem como revela situações relacionadas ao cotidiano do eu-lírico e 
suas inquietações acerca dos mais diversos assuntos: o amor, os relacionamentos, a função social da mulher negra, e a condição intelectual da artista afrodescendente, entre outros. Os versos do poema "Inusitada" exemplificam tal representação.

Traços autobiográficos ("Sou uma mulher no Planalto Central") marcam os versos desse poema; assim, a interação entre escritura e experiência destaca o lugar de fala e a resistência e a ação em um espaço inóspito. As metáforas concernentes à descrição de Brasília contrastam com a vivacidade da cor e da sensibilidade poética do eu-lírico. Essa mulher inusitada em Brasília é também a voz inusitada que ganha cada vez mais espaço no cenário cultural brasileiro. A voz poética vislumbra a ressignificação da visão estereotipada da mulher negra, e também a inscrição dessa mulher como sujeito no corpus literário, atribuindo-lhe o poder de, enfim, expor suas experiências na sociedade em que vive. Escrever é reescrever a história de um ponto de vista diferente do apresentado nas visões dominantes, é resgatar subjetividades coletivas, é valorizar a negritude.

As metáforas "Investindo contra a aridez do deserto" e "brotar em qualquer porto", presentes na penúltima estrofe, remetem à adoção de uma visão de mundo própria e distinta da do branco, à superação da cópia de modelos europeus e à assimilação cultural imposta como única via de expressão. Ao superar o discurso do colonizador em seus matizes passados e presentes, a perspectiva afro-brasileira configura-se como discurso da diferença e atua como elo importante dessa cadeia discursiva, como afirma Duarte (2010).

A análise dos poemas permitiu evidenciarmos a singularidade da escrita de Sobral. A questão identitária emerge em seu fazer literário por meio de uma voz que exalta a negritude e contesta as diversas formas de preconceito e racismo. A literatura é poder, poder de convencimento, de alimentar o imaginário; a literatura é fonte inspiradora do pensamento e da ação. Talvez possamos ver o ser humano em sua profundidade, para além da aparência do ser e do ter, como sugere a voz poética do poema "Miradouros". 
A escritura de Sobral faz-nos refletir sobre a literatura negra de afirmação que tem a identidade e a negritude como tema central. Por meio de uma escrita que tem cor, que é a negritude viva e atenta aos estereótipos e estigmas que ainda perseguem os negros no Brasil. Assim, Sobral demarca seu espaço no território árido da literatura brasileira.

A afirmação da identidade negra contrapõe-se à estereotipia, à objetificação, à desvalorização do negro, à imposição de lugares sociais e à invisibilização dos afrodescendentes no Brasil. Nos poemas de Cristiane Sobral, percebemos um olhar atento ao racismo, pois a luta ainda não foi vencida, como a poeta escreve: "criar é um verbo de ação" (SOBRAL, 2017, p. 104); e é preciso presentificar o passado, dialogar com as vozes que demarcaram espaços e reinventar o compasso da história.

A poesia negra de autoria feminina representa a diversidade e a esperança, como a voz poética do poema "Resistência" afirma: "amanhã estaremos vivas / protestando contra a violência /porque vamos encher a terra com os nossos filhos" (SOBRAL, 2017, p. 73). Esses versos prenhes de esperança nos fazem acreditar em um mundo melhor, em uma terra povoada de negritude livre subvertendo a herança cultural racista disfarçada de paz e cordialidade.

A relevância da obra poética de Cristiane Sobral está pautada em seu engajamento político e social, na autogestão da imagem da autora, na representatividade e visibilidade da escrita de autoria negra e feminina. Desse modo, torna-se necessário cultivar a voz feminina negra, dar visibilidade às potencialidades de seus discursos em meio a outros, já perpassados e instituídos. 


\section{Referências bibliográficas}

CUTI [Luiz Silva]. Literatura negro-brasileira. São Paulo: Selo Negro, 2010.

DUARTE, Eduardo de Assis. Literatura e afrodescendência no Brasil: antologia crítica. Belo Horizonte: UFMG, 2011, Volume 4: História, Teoria, Polêmica.

MUNANGA, Kabengele. Negritude: usos e sentidos. Belo Horizonte: Autêntica, 2009.

RIBEIRO, Djamila. O que é lugar de fala? Belo Horizonte: Letramento: Justificando, 2017.

SOBRAL, Cristiane. Espelhos, miradouros, dialéticas da percepção. Brasília: Dulcina Editora, 2011.

. Não vou mais lavar os pratos. In: RIBEIRO, Esmeralda; BARBOSA, Márcio. (Org.). Cadernos Negros 23. São Paulo: Quilombhoje, 2000.

. Não vou mais lavar os pratos. Brasília: Editora Thesaurus, 2010.

. O tapete voador. Rio de Janeiro: Malê, 2016.

. Olhos de azeviche. Rio de Janeiro: Malê, 2017.

. Só por hoje vou deixar meu cabelo em paz. Brasília: Ed. Teixeira, 2014.

. Terra negra. Rio de Janeiro: Malê, 2017.

Recebido em 05/04/2019

Aceito em 25/07/2019 